\title{
KEBIJAKAN HUTAN INDONESIA ERA JOKO WIDODO SEBAGAI IMPLEMENTASI PARIS AGREEMENT
}

\author{
Afrizal dan Dadang Mashur \\ FISIP Universitas Riau, Kampus Bina Widya Km. 12,5 Simpang Baru Panam, Pekanbaru 28293
}

\begin{abstract}
The Policy of the Forest in Indonesian in Joko Widodo Era as the Implementation of Paris Agreement. Paris Agreement which agreed by Indonesia and others country gave new dream for world future after increased the climate change in the world. In This script will look at how the policy of the forest in Indonesian in Joko Widodo era as the implementation of paris agreement. This reasech use methodology of qualitative with method the literatur study. The policy of the forest in Indonesian in Jokowi era with have made the constitution of Republic Indonesia (Nomor 16 Tahun 2016) about validation of paris Agreement To The United Nations Framework Convention On Climate Change. That constitution valided in Jakarta, at October $24^{\text {th }} 2016$ by Joko Widodo and Yasonna H. Laoly.
\end{abstract}

Abstrak: Kebijakan Hutan di Indonesia era Joko Widodo sebagai Implementasi Paris Agreement. Paris Agreement yang telah disepakati oleh Indonesia dan negara-negara lainnya tentu memberikan harapan baru bagi masa depan negara setelah meningkatnya isu perubahan iklim dunia. Maka dalam penulisan ini akan melihat bagaimana kebijakan hutan di Indonesia pada masa Joko Widodo sebagai implementasi Paris Agreement. Penelitian ini menggunakan metodologi kualitatif dengan metode studi literatur. Kebijakan hutan di Indonesia era Jokowi adalah dengan mengeluarkan Undang-Undang Republik Indonesia Nomor 16 Tahun 2016 tentang pengesahan Paris Agreement To The United Nations Framework Convention On Climate Change (persetujuan Paris atas konvensi kerangka kerja Perserikatan Bangsa-Bangsa mengenai perubahan iklim). Undang-undang ini disahkan di Jakarta pada tanggal 24 Oktober 2016 oleh Joko Widodo dan Yasonna H. Laoly.

Kata Kunci: implementasi, kebijakan hutan, Paris Agreement

\section{PENDAHULUAN}

Indonesia sebagai negara yang dikarunia keindahan dan kekayaan alam yang luas dan melimpah, serta faktor lingkungan hidup baik tumbuhan, hewan maupun hutan yang asri membuat Indonesia menjadi “paru-paru” dunia yang keberadaannya sama penting seperti hutan Amazon di Amerika Latin dan hutan Congo di belahan Afrika Tengah. Faktor inilah yang menyebabkan pentingnya Indonesia ikut dalam Paris Agreement akan tetapi bukan hanya menandatanganinya, namun juga meratifikasi dan membuat undang-undang kehutanan yang mengatur implementasinya di Indonesia.

Paris Agreement merupakan salah satu rezim internasional di bidang lingkungan yang merupakan hasil kesepakatan negara-negara anggota Perserikatan Bangsa Bangsa (PBB) dan para ahli di dunia melalui sebuah proses interaksi dan negosiasi. Setelah Perjanjian Paris terbentuk, negara-negara yang menyepakatinya beserta aktor-aktor internasional terkait secara otomatis telah menerima kewajibankewajiban tertentu yang menjadi konsekuensi bagi negara-negara atau aktor yang menjadi bagian dari rezim internasional tersebut. negara memiliki "Kecenderungan untuk mamatuhi" karena faktor efisiensi, kepentingan dan norma dalam perjanjian tersebut. Faktor efisiensi menjelaskan bahwa akan lebih efisien bagi negara untuk berkomitmen terhadap sebuah perjanjian karena dampak rusaknya reputasi negara akan sangat kuat ketika negara tidak mematuhi kesepakatan yang telah dibuat (Chayes, Abram \& Chayes, Antonia Handler, 1993).

Meratifikasi Kesepakatan Paris berarti mengambil tempat di dalam forum pengambilan keputusan untuk Konferensi Para Pihak (COP) yang diadakan di bawah payung Kesepakatan Paris, atau yang nantinya akan disebut sebagai Conference of Parties serving as the Meeting of the Parties to this Agreement (CMA). CMA, serupa dengan CMP untuk Protokol 
Kyoto, adalah forum pengambilan keputusan tertinggi untuk mengimplementasikan Kesepakatan Paris. Adapun bagi megara Pihak yang tidak meratifikasi Kesepakatan Paris tidak akan memiliki hak suara di dalam forum tersebut. Dalam kasus CMP, Amerika Serikat tidak menjadi bagian dan tidak memiliki hak suara terkait implementasi Protokol Kyoto, dikarenakan Amerika Serikat tidak meratifikasi Protokol Kyoto. Itu sebabnya, sangat penting bagi suatu negara untuk meratifikasi Kesepakatan Paris sehingga memiliki suara dan dapat terlibat dalam pembahasan tentang penentuan mekanisme, penyusunan kelengkapan (modalitas) yang diperlukan untuk mengimplementasikan Kesepakatan Paris yang nantinya akan dibahas di CMA.

Perbedaan pada status Indonesia jika meratifikasi Kesepakatan Paris dibandingkan dengan ratifikasi Konvensi Perubahan Iklim (UNFCCC) atau Protokol Kyoto. Dengan meratifikasi Kesepakatan Paris Indonesia akan terikat dengan segala ketentuan yang berlaku, termasuk ketentuan melakukan penurunan emisi gas rumah kaca secara konsisten sebagaimana yang akan dijanjikan dalam naskah Nationally Determined Contribution (NDC).

Kesepakatan Paris menetapkan proses kajian berkala. Dengan demikian NDC yang dikomunikasikan kepada UNFCCC akan ditinjau bersama-sama setiap lima tahun. Dari proses ini diharapkan upaya atau ambisi dari masing-masing negara Pihak akan meningkat seiring dengan berjalannya waktu. Itu sebabnya, akan lebih mudah bagi Indonesia untuk menyusun NDC dengan mengacu pada perencanaan jangka panjang dan menengah yang sudah ada. Misalnya, target dan aksi mitigasi sektor energi di NDC disusun dengan mempertimbangkan dan mengacu pada Kebijakan Energi Nasional dan Rencana Umum Energi Nasional (RUEN), Rencana Pembangunan Jangka Panjang (RPJP) serta mempertimbangkan hasil dari implementasi Rencana Aksi Nasional untuk Pengurangan Emisi Gas Rumah Kaca (RAN GRK).

Meratifikasi Kesepakatan Paris juga memberi kesempatan bagi Indonesia mema- hami secara utuh dampak perubahan iklim yang akan terjadi di Indonesia, termasuk potensi kehilangan dan kerusakan yang akan terjadi, jika temperatur rata-rata bumi meningkat lebih dari 2 derajat Celcius. Ini adalah modal baik untuk menetapkan sektor-sektor prioritas di masa depan, sasaran dan ragam intervensi yang perlu diambil untuk meningkatkan daya lenting dan mengurangi resiko dampak perubahan iklim. Meratifikasi Kesepakatan Paris berarti Indonesia juga memikirkan masa depan bangsa dengan berkontribusi secara global untuk mengurangi emisi gas rumah kaca, demi mengurangi dampak perubahan iklim yang mungkin terjadi di Indonesia.

Kerjasama erat dan komunikasi dari eksekutif, yang diwakili oleh Kementerian Luar Negeri dan Kementerian Lingkungan Hidup dan Kehutanan) dan legislatif yaitu DPR dan DPD merupakan kunci untuk Indonesia dapat meratifikasi Kesepakatan Paris melalui instrumen Undang-Undang pada COP-22 yang berlangsung mulai tanggal 7 November 2016. Tidak bisa ditinggalkan juga adalah kepedulian dan dukungan publik untuk memastikan Indonesia mengambil tanggung jawab yang sesuai dengan kemampuan dan situasi nasional untuk mengatasi tantangan perubahan iklim global.

\section{METODE}

Metode penelitian yang digunakan adalah metode kulitatif. Metode kualitatif lebih dapat menyesuaikan diri dengan banyak penajaman pengaruh bersama dan terhadap pola-pola nilai yang dihadapi. Jadi, penelitian kualitatif lebih bisa menginterpretasi data yang didapat dengan menyesuaikan dan menghubungkan kepada permasalahan yang ada. Penelitian kualitatif lebih banyak mementingkan proses dari pada hasil. Hal ini disebabkan oleh hubunganhubungan bagian-bagian yang sedang diteliti akan jauh lebih jelas apabila diamati dalam proses (Maleong, 2004).

Teknik penelitian menggunakan teknik penelitian library research atau kepustakaan. Teknik pustaka ini dilakukan dengan pengumpulan data dari literatur berupa buku-buku, 
majalah-ajalah surat kabar dan kunjungan ke situs internet serta sumber lain yang menunjang penelitian.

\section{HASIL DAN PEMBAHASAN}

Kesepakatan Paris yang mengadopsi prinsip applicable to all Parties (berlaku untuk seluruh Pihak), memberikan pekerjaan rumah yang cukup besar untuk negara berkembang. Negara-negara berkembang, yang dalam konvensi disebut sebagai negara non-Annex, harus ikut serta dalam upaya global untuk memitigasi emisi gas rumah kaca (GRK) dan pada saat yang bersamaan harus beradaptasi menghadapi dampak perubahan iklim. Untuk itu Indonesia harus bertransformasi dengan cepat, menuju pembangunan negara yang rendah karbon dan emisi gas rumah kaca sehingga dapat mengurangi dampak perubahan iklim.

Indonesia sebelumnya sudah meratifikasi Konvensi Perubahan Iklim melalui UndangUndang Nomor 6 Tahun 1994 tentang Pengesahan Konvensi Kerangka Kerja PBB Mengenai Perubahan Iklim (United Nations FrameworkConvention on Climate Change) dan Protokol Kyoto melalui UndangUndang Nomor 17 Tahun 2004 tentang Pengesahan Protokol Kyoto. Dalam rangka memberikan landasan hukum bagi komitmen pemerintah dan pengakuan hukum atas keikutsertaan dalam perjanjian internasional dalam hal ini Persetujuan Paris, maka sesuai dengan ketentuan peraturan perundang-undangan yang berlaku bahwa pengesahan Persetujuan Paris harus ditetapkan dalam suatu Undang-Undang. Hal ini terkait dengan substansi dalam Persetujuan Paris yang mengatur tentang norma lingkungan hidup.

Menteri Lingkungan Hidup dan Kehutanan, Siti Nurbaya, sebagai perwakilan Indonesia menandatangani perjanjian Paris Agreement tentang perubahan iklim.Indonesia menjadi salah satu negara yang langsung mendeposit instrument ratifikasi.Penandatanganan tersebut digelar di markas PBB, New York. Menteri Lingkungan Hidup dan Kehutanan Indonesia, Siti Nurbaya menegaskan bahwa Indonesia dapat menjadi salah satu negara dari 55 negara pertama yang melakukan ratifikasi dikarena- kan pertimbangan pentingnya subyek lingkungan sesui UUD 1945 untuk menyediakan lingkungan yang baik bagi warga negara.

Sistem hukum nasional di Indonesia juga memuat prihal ratifikasi perjanjian internasional dan itu diatur dalam Undang-Undang Nomor 24 Tahun 2000 tentang Perjanjian Internasional. Ratifikasi perjanjian internasional dilakukan dengan Undang-Undang atau Peraturan Presiden. Paris Agreement sebagai dasar hukum upaya antisipasi perubahan iklim baik dalam lingkup global maupun nasional disahkan dalam bentuk Undang-Undang.

Pada Rabu, 19 Oktober 2016 Dewan Perwakilan Rakyat (DPR) Republik Indonesia, melakukan sidang paripurna DPR RI yang ke-9 masa sidang pertama tahun 20162017, dan membahas pengambilan keputusan atas Rancangan Undang-undang Pengesahan Paris Agreement to the United Nations Frame Works on Climate Change atau Persetujuan Paris atas Konvensi Kerangka Kerja PBB mengenai Perubahan Iklim menjadi Undangundang.

Setelah melakukan pengambilan keputusan tingkat satu, diikuti dengan pengambilan keputusan tingkat dua yang dilakukan pada Rapat Paripurna DPR RI dan dihadiri oleh pemerintah yang diwakili oleh Menteri Lingkungan Hidup dan Kehutanan serta beberapa pejabat Esselon I dari Kementerian Luar Negeri dan Kementerian Hukum dan HAM.

Badan musyawarah DPR-RI pada tanggal 11 Oktober 2016 telah menugaskan Komisi Tujuh DPR RI yang di ketuai Gus Irawan Pasaribu untuk melakukan pembicaraan tahap pertama atas RUU Persetujuan Paris atas Konvensi Kerangka Kerja tentang Perubahan Iklim. Persetujuan Paris merupakan persetujuan internasional tentang perubahan iklim yang bertujuan menekan laju naiknya suhu bumi sebesar $2^{\circ} \mathrm{C}$

Terdapat beberapa landasan dalam mengimplementasikan Paris Agreement menjadi rancangan undang-undang diantaranya:

1. Landasan filosofis

Pemerintah dan negara Indonesia dalam salah satu jabaran eka prasetya panca karsa 
dalam Pancasila yaitu sila "kemanusiaan yang adil dan beradab” menyebutkan bahwa bangsa Indonesia melihat dirinya sebagai bagian dari seluruh umat manusia, karena itu dikembangkan sikap hormat-menghormati dan bekerja sama dengan bangsa lain. pengesahan persetujuan paris menunjukkan komitmen Indonesia sebagai bagian dari umat manusia dunia untuk bekerja bersama dengan negara-negara di dunia untuk mengatasi persoalan bersama, yaitu pemanasan global. bangsa Indonesia bersama dengan negara-negara dunia berkomitment untuk menjaga kenaikan suhu global abad ini di bawah $2^{\circ} \mathrm{C}$ dan mendorong upaya untuk membatasi kenaikan suhu bumi lebih jauh ke $1,5^{\circ} \mathrm{C}$ di atas tingkat pra-industri.

Tujuan negara Indonesia sebagaimana yang disebutkan didalam pembukaan UUD 1945 yaitu untuk melindungi segenap bangsa Indonesia dan seluruh tumpah darah Indonesia dan untuk memajukan kesejahteraan umum, mencerdaskan kehidupan bangsa, dan ikut melaksanakan ketertiban dunia yang berdasarkan kemerdekaan, perdamaian abadi dan keadilan sosial. Pengesahan persetujuan Paris ini menjadi pembuktian pemerintah untuk melindungi segenap bangsa indonesia dan seluruh tumpah darah Indonesia dari dampak-dampak merugikan yang terjadi dari kenaikan suhu global. pengesahan ini menunjukkan peran aktif pemerintah dan negara Indonesia dalam menjaga ketertiban dunia dari dampak merugikan pemanasan global.

\section{Landasan sosiologis}

Keberhasilan dalam stabilisasi konsentrasi Gas Rumah Kaca (GRK) dan beradaptasi terhadap dampak merugikan perubahan iklim sesuai dengan tujuan UNFCC dan Persetujuan Paris merupakan upaya bersama di tingkat internasional, nasional dan daerah. Keberhasilan ini dapat diperoleh melalui kerjasama antar negara di tingkat internasional, antar kementerian dan lembaga serta masyarakat luas pada tingkat nasional dan daerah.

Dasar utama dalam meningkatkan kohesi sosial antar lembaga dan antar individu serta masyarakat dalam kehidupan berbangsa dan bernegara dipraktekkan dalam model pe- ngambilan keputusan melalui musyawarah dan mufakat. Musyawarah dalam pengambilan keputusan, melakukan tindakan dan aksi perubahan iklim merupakan modal dasar dalam pelaksanaan Persetujuan Paris. Selain itu, di tengah-tengah masyarakat juga telah mengenal prinsip tolong menolong dan gotong royong dalam menyelamatkan kemaslahatan bersama.

Pengimplementasian isi Persetujuan Paris dapat dilakukan pada tingkat individu, masyarakat, lembaga dan negara. Pada tingkat individu, setiap orang harus dapat menjadi agen perubahan dengan mengubah gaya hidup menjadi ramah lingkungan, serta menciptakan polapola kehidupan yang adaptif terhadap dampak perubahan iklim. Pada tingkat lembaga dapat dilakukan melalui perubahan kebijakan internal dengan menerapkan pengurangan emisi pada setiap bidang.

\section{Landasan Yuridis}

Pengesahan Persetujuan Paris ini dilakukan untuk memenuhi kebutuhan hukum dalam rangka implementasinya baik dalam tataran internasional maupun nasional. Sesuai dengan Pasal 10 Undang-Undang Nomor 24 Tahun 2000 tentang Perjanjian Internasional, pengesahan perjanjian internasional dilakukan dengan undang-undang apabila berkenaan dengan: (a) masalah politik, perdamaian, pertahanan, dan keamanan negara; (b) perubahan wilayah atau penetapan batas wilayah negara Republik Indonesia; (c) kedaulatan atau hak berdaulat negara; (d) hak asasi manusia dan lingkungan hidup; (e) pembentukan kaidah hukum baru; dan (f) pinjaman dan/atau hibah luar negeri. Dengan dasar Undang-Undang Nomor 24 Tahun 2000 tersebut, mengingat materi substansi Persetujuan Paris adalah perubahan iklim dan telah masuk bidang lingkungan hidup, maka bentuk hukum pengesahan Persetujuan Paris adalah menggunakan Undang-Undang.

Pengesahan Persetujuan Paris atas Konvensi Kerangka kerja tentang Perubahan Iklim telah dibahas dalam rapat kerja Komisi VII DPR RI yang di Ketua oleh Gus Irawan Pasaribu pada tanggal 11 Oktober 2016 dan telah menghasilkan Rancangan Undang-Undang (RUU). RUU ini penting untuk segera disahkan men- 
jadi Undang-Undang (UU) karena didasari pada kondisi Indonesia yang merupakan negara kepulauan yang sangat rentan terhadap seluruh dampak perubahan iklim. Perubahan iklim menjadi perhatian banyak pihak, dan merupakan keniscayaan yang terjadi semakin cepat dan telah berdampak langsung pada manusia. Untuk itu Komisi VII DPR RI setuju untuk mengesahkan perjanjian ini dari RUU menjadi UU dan selanjutnya diserahkan proses pengambilan keputusannya pada Rapat Paripurna.

Indonesia memiliki peraturan perundangundangan yang berkaitan dan mendukung pelaksanaan Persetujuan Paris. Peraturan itu didukung oleh perundang-undangan nasional yang terkait, antara lain:

1. Undang-Undang Nomor 5 Tahun 1960 tentang Peraturan Dasar Pokok-Pokok Agraria;

2. Undang-Undang Nomor 5 Tahun 1990 tentang Konservasi Sumber Daya Alam Hayati dan Ekosistemnya;

3. Undang-Undang Nomor 6 Tahun 1994 tentang Pengesahan United Nations Framework Convention on Climate Change (Konvensi Kerangka Kerja Perserikatan Bangsa-Bangsa mengenai Perubahan Iklim);

4. Undang-Undang Nomor 41 Tahun 1999 tentang Kehutanan;

5. Undang-Undang Nomor 22 Tahun 2001 tentang Minyak dan Gas;

6. Undang-Undang Nomor 17 Tahun 2004 tentang Pengesahan Kyoto Protocol to the United NationsFramework Convention on Climate Change(Protokol Kyoto atasKonvensi Kerangka Kerja Perserikatan Bangsa-Bangsa tentang Perubahan Iklim);

7. Undang-Undang Nomor 30 Tahun 2007 tentang Energi;

8. Undang-Undang Nomor 18 Tahun 2008 tentang Pengelolaan Sampah;

9. Undang-Undang Nomor 4 Tahun 2009 tentang Pertambangan Mineral dan Batubara;

10.Undang-Undang Nomor 31 Tahun 2009 tentang Meteorologi, Klimatologi, dan Geofisika;
11.Undang-Undang Nomor 32 Tahun 2009 tentang Perlindungan dan Pengelolaan Lingkungan Hidup;

12.Undang-Undang Nomor 18 Tahun 2013 tentang Pencegahan dan Pemberantasan Perusakan Hutan.

Atas dasar UU tersebut, maka hasil kesepakatan DPR mengeluarkan UU RI Nomor 16 Tahun 2016 tentang pengesahan paris Agreement To The United Nations Framework Convention On Climate Change (persetujuan paris atas konvensi kerangka kerja PBB mengenai perubahan iklim). UU ini disahkan di jakarta, pada tanggal 24 Oktober 2016 oleh Presiden RI Joko Widodo dan diundangkan di Jakarta, pada tanggal 25 Oktober 2016 Menteri Hukum dan Hak Asasi Manusia RI, Yasonna H. Laoly.

Nationally Determined Contribution (NDC) merupakan bagian yang tidak terpisahkan dari Paris Agreement, perjanjian Paris pasal 1 menyebutkan dalam rangka membangun kepercayaan mempromosikan NDC yang efektif maka dibangunlah kerangka kerja transparansi (an anhanced transparency framework) untuk aksi (mitigasi dan adaptasi) serta support (pendanaan, teknologi, capacity building). Dalam mencapai target reduksi emisi 29\% maka dibentuklah program NDC untuk mendukung dan mewujudkan implementasi Paris Agreement. Program-program utama NDC itu adalah:

a. Program Pengembangan Ownership dan Komitmen Kementerian/Lembaga, Pemerintah Daerah, dan Lembaga Legislatif

Setelah secara nasional ditetapkan komitmen reduksi emisi 29\% unconditional dan $41 \%$ conditional, secara mendasar, implementasi reduksi emisi untuk mencapai komitmen tersebut membutuhkan dukungan dan komitmen setiap sektor dan sub nasional. Tanpa ada dukungan kementerian/lembaga serta pemerintah daerah, ambisi reduksi emisi tidak dapat direalisasikan. Membangun Ownership dan komitmen kementerian/lembaga dan pemerintah daerah, baik pemerintah provinsi dan pemerintah kabupaten menjadi landasan keberhasilan implementasi NDC. 
Melalui program ini, kementerian/lembaga dan pemerintah daerah menyusun $S u b$ National Commitment yang memperhatikan konteks lokal yang dikonstruksikan dari rasionalitas ekosistem, sosial, dan ekonomi regional di masing-masing wilayah provinsi dan kabupaten/kota.Sub-National Commitment ini disusun berdasarkan kerangka pembangunan berkelanjutan daerah, untuk menjamin bahwa komitmen reduksi emisi juga mencerminkan komitmen peningkatan kesejahteraan masyarakat dan kepentingan daerah lainnya.

Sejalan dengan apa yang disepakati di Paris mengenai Non-Party Stakeholders, bahwa disamping Pemerintah daerah, sektor swasta, masyarakat sipil, dan lembaga keuangan didorong untuk meningkatkan upaya yang telah dilakukan, dengan dukungan kebijakan nasional masing-masing negara.

b. Program Penyusunan Kerangka Kerja dan Jaringan Komunikasi NDC

Implementasi NDC untuk mencapai target komitmen nasional, yang merupakan agregasi implementasi NDC di tingkat SubNational, sedangkan secara kelembagaan, tidak memungkinkan upaya reduksi emisi hanya menjadi tanggungjawab atau dilaksanakan oleh satu entitas saja, namun membutuhkan kontribusi semua pihak. Konektivitas dan sinergi kerjasama antara para pihak menjadi kunci keberhasilan implementasi NDC di seluruh wilayah Indonesia. Kerangka kerja implementasi NDC atau NDC's Implementation Framework menjadi kebutuhan bersama setelah Sub-National Commitment seluruh Indonesia disusun. Substansi NDC’s Implementation Framework adalah membangun koordinasi antar sektor dan wilayah tanpa perlu membangun kelembagaan baru untuk implementasi NDC.

Seperti diuraikan di atas, yang sangat penting adalah koordinasi antar sektor dan wilayah tanpa harus membangun kelembagaan baru tetapi penguatan kelembagaan yang telah ada. Dengan didorongnya peran Non-Party Stakeholders termasuk Non-State Actors, setiap negara termasuk Indonesia akan memasuki era Tata Kelola Baru Pengendalian
Perubahan Iklim, yang penyiapannya menjadi bagian dari proses penyiapan NDC.

\section{c. Program EnablingEnvironment}

Terdapat beberapa kondisi pemungkin utama untuk keberhasilan implementasi NDC, yaitu (1) Pelaksanaan Kajian Lingkungan Hidup Strategis (KLHS) sebagai mandat UndangUndang No. 32 tahun 2009 tentang Perlindungan dan Pengelolaan Lingkungan Hidup untuk menjamin integrasi pembangunan berkelanjutan dalam tentang tata ruang, RPJMN/ RPJMD, Penetapan kawasan Hutan, termasuk kebijakan, rencana, dan program utama lainnya yang berpotensi memberikan dampak terhadap lingkungan, sosial, dan ekonomi, (2) Penguatan kelembagaan dalam pengelolaan Daerah Aliran Sungai (DAS), (3) KLHS Kebijakan Energi Nasional (KEN), Rencana Usaha Penyediaan Tenaga Listrik (RUPTL), Rencana Umum Energi Nasional (RUEN), dan Rencana Umum Energi Daerah (RUED), dan (4) Penyusunan Indonesia's NasionalStrategy for Sustainable Development. Kebijakan, Rencana, dan Program(KRP) yang menjadi sasaran dalam program kondisi pemungkin adalah KRP yang sangat mempengaruhi keberhasilan implementasi NDC, namun memiliki kemungkinan tidak terintegrasi dengan program NDC.

d. Program Pengembangan Kapasitas

Kapasitas penting yang dibutuhkan dalam penyiapan dan implementasi NDC yang dapat ditempuh melalui penguatan kelembagaan dan kapasitas SDM yaitu (1) perhitungan emisi sektoral/wilayah, (2) Pembuatan model NDC sektoral/daerah untuk proyeksi emisi BAU dan skenario NDC unconditional dan conditional, (3) Penyusunan Rencana Implementasi NDC sektoral/wilayah, (4) Review implementasi atau MRV NDC, dan (5) Integrasi Rencana Implementasi NDC sektoral/ wilayah ke dalam Rencana Pembangunan Nasional dan Daerah.

e. Program One Data Policy Emisi Gas Rumah Kaca

Berbasiskan kerangka kerja dan jaringan komunikasi penyiapan dan implementasi NDC, data emisi nasional, sektoral dan wilayah, 
dikelola dengan konsep One Data Policy, sehingga data dan informasi yang diperoleh, disusun, dikumpulkan, dan dikomunikasikan dengan para pihak dikelola secara terpusat dan tunggal.

Sesuai mandatnya dan dengan telah beroperasinya SIGN-SMART di Kementerian Lingkungan Hidup dan Kehutanan, maka tata kelola One Data emisi GRK terpusat di KLHK (dalam hal ini Direktorat Jenderal Pengendalian Perubahan Iklim/Ditjen PPI). Koordinasi dengan Komponen entitas utama NDC's Preparatory and Implementation Framework lainnya yaitu denganKelompok Kerja atau Unit Penanggung Jawab Perubahan Iklim Kementerian/Lembaga dan Kelompok Kerja atau Unit Penanggung Jawab Perubahan Iklim Daerah (provinsi/Kabupaten/Kota). Disesuaikan dengan ruang lingkup sumber emisi dalam dokumen NDC, One Data Policy Emisi GRK memiliki 5 (lima) modul data emisi, yaitu modul energi, industri, pertanian, penggunaan lahan, perubahan penggunaan lahan dan kehutanan (LULUCF), dan modul limbah. Akuntabilitas Program ini merupakan bagian dari praktik good governance yang sedang diperjuangkan di dalam negeri dan merupakan bagian dari Enhanced Tranparancy Framework (ETF) yang telah disepakati dalam Perjanjian Paris.

f. Program Penyusunan Kebijakan, Rencana dan Program (KRP) Intervensi

Reduksi emisi dalam NDC Indonesia dilakukan terhadap 5(lima) sumber emisi yang dikategorikan sesuai ruang lingkupnya dalam dokumen INDC, yaitu energi, industri, pertanian, penggunaan lahan-perubahan penggunaan lahan dan kehutanan (LULUCF), dan limbah. Sesuai dengan UU No. 25 tahun 2004 tentang Sistem Perencanaan Pembangunan Nasional, implementasi NDC perlu diintegrasikan ke dalam sistem perencanaan pembangunan untuk menjamin sinergi antar instansi, termasuk penganggaran, agar dapat direalisasikan di lapangan. Setiap skenario intervensi yang disusun dalam model NDC.

Perlu dituangkan dalam bentuk KRP masing-masing instansi terkait, untuk men- jamin program-program tersebut dapat menjadi program dan kegiatan dalam APBN dan APBD.Selain itu, juga untuk menjamin bahwa program-program yang disusun berdasarkan skenario intervensi dalam model dapat diimplementasikan di kondisi nyata di lapangan. Penyusunan KRP intervensi untuk setiap sektor dikelola melalui NDC's Implementation Framework, dengan 5 (lima) kategori bidang KRP, yaituKRP bidang energi, industri/IPPU, pertanian, LULUCF, dan KRP bidang limbah.

\section{SIMPULAN}

Isu perubahan iklim dunia (climate change) telah dibahas dalam Paris Agreement. Kesepakatan Paris Agreement merupakan basis legal bagi Indonesia untuk membuat kebijakan dalam bentuk UU, sehingga pengendalian perubahan iklim di Indonesia dapat di implementasikan.

Indonesia yang dikarunia sumber daya alam yang luas dan melimpah, serta faktor lingkungan hidup seperti, hutan tropis yang menjadi paru-paru dunia. Kekayaan sumber daya alam baik di darat maupun laut juga mempengaruhi Indonesia dalam mengambil berbagai inisiatif pada tingkat regional maupun internasional baik dengan maksud melindungi, mengkonservasi maupun dalam penggunaannya yang berkelanjutan (sustainable use), oleh sebab itulah Indonesia ikut meratifikasi Paris Agreement.

Indonesia telah membuat komitmenkomitmen untuk mengurangi emisi GRK. Komitmen untuk mengurangi emisi GRK, ini ditunjukkan dengan meratifikasi Paris Agreement. Hasil kesepakatan DPR RI adalah bukti adanya pengesahan paris Agreement To The United Nations Framework Convention On Climate Change (persetujuan paris atas konvensi kerangka kerja PBB mengenai perubahan iklim) yaitu dengan dikeluarkannya UU RI Nomor 16 Tahun 2016. UU ini disahkan di jakarta, pada tanggal 24 Oktober 2016 oleh Presiden RI Joko Widodo dan diundangkan di Jakarta, pada tanggal 25 Oktober 2016 Menteri Hukum dan Hak Asasi Manusia RI, Yasonna H. Laoly. 
Selain UU, mplementasi paris Agreement juga melalui program Nationally Determined Contribution (NDC). NDC merupakan bagian yang tidak terpisahkan dari Paris Agreement, perjanjian Paris pasal 1 menyebutkan dalam rangka membangun kepercayaan mempromosikan NDC yang efektif maka dibangunlah kerangka kerja transparansi untuk mitigasi dan adaptasi serta support (pendanaan, teknologi, capacity building) serta peran berbagai stakeholder dalam pengelolaan hutan dan lingkungan untuk mengatasi perubahan iklim.

\section{DAFTAR RUJUKAN}

Andreas Pramudianto, 2016, Dari Protocol Kyoto 1997 Hingga Paris Agreement: Dinamika Diplomasi Perubahan Iklim Global Dan ASEAN Menuju 2020. Global vol.18 No. 1.

BPKP,.”Undang-Undang Republik Indonesia Nomor 17 Tahun 2004 Tentang Pengesahan Kyoto Protocol To The United Nations Framework C'onvention On Climate Change (Protokol Kyoto atas Konvensi Kerangka Kerja Perserikatan
Bangsa-Bangsa Tentang Perubahan Iklim). .

Chayes, Abram.,\& Chayes, Antonia Handler, 1993. On Compliance.International OrganizationVol 47 Edisi 2, 175-205.

Direktorat Jendral Bidang "Pengendalian Iklim Kementerian Hutan dan Lingkungan Hidup. 2016. Perubahan Ilkim, Perjanjian Paris Dan Nationally Determined Contribution".

Lexy J. Maleong, 2004, Metodologi Penelitian Kualitatif, Bandung: Remaja Rosdakarya.

Rizqi Abdul Majid Dan Imam Ghozali, "Analisis Factor-Faktor Yang Memperngaruhi Pengungkapan Emisi Gas Rumah Kaca Di Indonesia “ Diponegoro Journal Of Accounting Volume 4, Nomor 4, Tahun 2015, Halaman 1-11 Http://Ejournal-S1. Undip.Ac.Id/Index.Php/Accountingissn (Online): 2337-3806.

Http://Ditjenppi.Menlhk.Go.Id/ Diakses Pada 27 Agustus 2018 Pukul 10:13 Wib

Http://Www.Dpr.Go.Id Diakses Pada 27

Agustus 2018 